\title{
Evaluation of Simple Visual Reaction Time of Different Colored Light Stimuli in Visually Normal Students
}

This article was published in the following Dove Press journal:

Clinical Optometry

\section{Rasoul Amini Vishteh \\ Ali Mirzajani \\ Ebrahim Jafarzadehpour \\ Samireh Darvishpour}

Department of Optometry, Iran University of Medical Sciences, School of Rehabilitation Sciences, Tehran, Iran
Correspondence: Ali Mirzajani Department of Optometry, Iran University of Medical Sciences, School of Rehabilitation Sciences, No. 24 Flat 2 .

I3th Alley, Behzad Hesari Street,

Mirdamad Avenue, Tehran, Iran

Tel +982122909608

Fax +98 2122220946

Email alimirzajani45@yahoo.com
Purpose: To evaluate the influence of colored light stimulus on simple visual reaction times. Methods: Simple visual reaction times of colored light stimuli were measured in 100 young Iranian females with the mean age of $23.02 \pm 3.45$ years (range from 18 to 30 years) in response to the four visual stimuli (red, green, yellow and blue light) by using Speed Anticipation and Reaction Tester (SART) software.

Results: The analysis of variance (ANOVA) test to compare visual reaction time showed a significant difference $(\mathrm{P}<0.001)$ between four colored light stimuli so that the maximum and minimum mean reaction times were obtained for blue- and red-colored light stimuli. Also, it was observed that the response latency for red color was significantly less compared to green color $(\mathrm{P}<0.05)$.

Conclusion: The present study showed that individuals do not respond to visual stimuli with different colors at the same speed, which may be due to different factors involved in the visual reaction time.

Keywords: reaction time, the color of stimulus

\section{Introduction}

The time interval between presentation of a stimulus and initiation of a voluntary motor response is referred to as the reaction time. ${ }^{1}$ The evaluation of the reaction time gives an idea of the integrity and processing capabilities of the central nervous system. ${ }^{2}$ It is an indirect indicator of the ability of the central nervous system to process and also is a simple tool to determine a person's motor-sensory relationship and related functions. ${ }^{3}$ In fact, the ability to detect or recognize one visual stimulus via one response can be assessed by measuring the reaction time that called simple visual reaction time. ${ }^{4}$ Reaction time measurement is used to evaluate a person's state of health as well as an individual's condition monitoring during their daily life to better performance of mental activities, decision-making and planning that necessary for driving, playing sport and other activities that require high focus and speed in instant decision. ${ }^{5-10}$

Although previous studies have generally not provided fixed values for reaction time due to the influence of various factors on its values, some researchers' findings showed that the average simple reaction times for college students are about $190 \mathrm{~ms}$ or more for visual stimuli. ${ }^{11,12}$

SVRT consists of various components. This is partly dependent on the rate of peripheral neural conduction including sensory processing speed and motor speed. Also, it incorporates central stimulus-response integration, which includes components 
such as response readiness, attention and alertness. ${ }^{13}$ Reaction time is influenced by different factors such as age, sex, left or right hand or handedness, central versus peripheral vision, type of receptor system involved, practice, fatigue, and intelligence of the subject. ${ }^{14}$ A review of previous studies suggests conflicting results regarding the duration of response to visual stimuli, with some studies reporting the faster response of reaction times for red color ${ }^{15}$ and others for green ${ }^{16}$ compared to each other.

Given the scarcity of literature and the contradictory results on the effect of object color on simple visual reaction times, further investigations are recommended by many researchers, so the present study was carried out to evaluate the simple visual reaction times of female students in four red, yellow, blue and green color stimuli.

\section{Materials and Methods}

This study was carried out in the Optometry Department of Iran University of Medical Sciences, Tehran, Iran. Written informed consent was obtained for each subject, and the research was conducted in accordance with the principles laid down in the Declaration of Helsinki. One hundred female students with the mean age of $23.02 \pm 3.45$ years (range from 18 to 30 years) were recruited from the students of the School of Rehabilitation Sciences, Tehran. All subjects participated in the study with the following conditions: predominantly right-handed, no history of drug or alcohol abuse, nonsmoker and without any history of medical body injury especially brain Injury. ${ }^{17}$ It is also noteworthy that all participants were selected among female students with clinically normal visual acuity, binocular fusion and color vision.

After mentioning the relevant history and detailed clinical examination, the study protocol was explained for participants. First uncorrected visual acuity (UCVA) was recorded using chart projector (HCP-7000; Huvitz, Gyeonggi-do, Korea) at a distance of 6 meters and patients with uncorrected visual acuity of 20/20 were selected. Also, all students underwent non-cycloplegic refraction with the HRK-7000 Auto refractometer (Huvitz, Gyeonggi-do, Korea) and the Heine Beta-200 retinoscope (HEINE Optotechnic, Hersching, Germany). Due to the effect of refraction and its correction on visual reaction time, ${ }^{18}$ emmetropic patients were selected in the present study.

The color blindness test was performed monocularly by the Ishihara color test (Kanehara and Co., Tokyo, Japan) under lighting conditions recommended by the International
Commission on Illumination. Patients entered the study without any color vision defects with the performance of this test.

Visual reaction times were recorded using custommade software called Speed Anticipation and Reaction Tester (SART) software. Inter-rater and intra-rater reliability of the SART software had already been assessed ${ }^{19}$. The participants were asked to sit 2 meters away from and in front of the LCD screen with a gray background which was used for displaying RT tests. In the time of the tests, after sitting at the desired distance in front of the 24-inch LCD monitor, participants placed their right forearm on the armrest and held the elbow joint at a 90-degree angle. The display panel is surrounded by four colored buttons so participants can press all four keys with their thumbs. The custom-made software was installed on a laptop computer which was connected to a 24-inch LCD monitor (Samsung syncmaster B243HD 24 inches, Korea) with standard RGB screen and a four-button joystick. The examiner randomly controlled and selected the tests through the laptop. Tasks in the present study included simple visual reaction time with four colored stimuli. Equiluminant colored stimuli of red, green, yellow and blue were displayed on an isoluminant gray background with a mean luminance of $23.86 \mathrm{~cd} /$ $\mathrm{m}^{2}$. In the visual reaction time test, participants had to press one of the four corresponding color buttons as soon as a color circle appeared on the screen with a gray background. After demonstrating the procedure, subjects were asked to respond to visual stimuli (four different colored circles) by pressing the response key with the index finger of their dominant hand. A millisecond timer of PC with the accuracy of 1 millisecond was activated when the stimulation was applied and deactivated when the subject pressed the button. Each stimulus was presented 30 times and their respective averages calculated. The duration of each stimulus presentation was 5 seconds with the interstimulus intervals of 10 seconds. Subjects were instructed to respond to the stimuli as quickly and accurately as possible.

It should be noted that this type of study has been conducted in previous years with fewer participants (62) and Stimulus (2 colored stimuli), suggesting different results. The present study involved more participants (100 subjects) and the use of 4 different colored stimuli for students.

All analyses were conducted using the SPSS software version 21 (SPSS Inc, Chicago, IL, USA). The normality of the distributions was assessed with the KolmogorovSmirnov test. The mean simple visual reaction times of red, green, yellow and blue stimuli were compared using 
analysis of variance (ANOVA) test. The significance level was set at 0.05 .

\section{Results}

In this study, the mean simple visual reaction time of four different colors of stimuli was calculated as $207.88 \pm 7.14$, $218.24 \pm 11.54,224.39 \pm 15.62$ and $216.02 \pm 2.49$ for red, green, blue and yellow stimuli, respectively. The relevant results are shown in Table 1.

A one-way between the subject's ANOVA was conducted to compare the simple visual reaction time of different colored stimuli (Table 2). The results showed a significant difference $(\mathrm{P}<0.001)$ between simple visual reaction times of red, green, blue and yellow stimuli. Comparison of the results of mean simple visual reaction time with LSD Post hoc test between different color stimuli showed that the reaction time of blue light stimulus was significantly higher than the other color stimuli so that the difference was significant in comparison with red, yellow and green $(\mathrm{P}<0.001)$ color stimuli. In addition, the minimum mean reaction time was related to red color stimuli with value of $207.88 \mathrm{~ms}$,

Table I Mean and Standard Deviation of Simple Visual Reaction Time

\begin{tabular}{|l|l|}
\hline Color of Stimuli & Mean (SD) \\
\hline Red & $207.88(7.14)$ \\
Green & $218.24(11.54)$ \\
Blue & $224.39(15.62)$ \\
Yellow & $216.02(12.49)$ \\
\hline
\end{tabular}

Abbreviation: SD, standard deviation

Table 2 Comparison of Simple Visual Reaction Time for Different Color Stimuli

\begin{tabular}{|l|l|l|l|}
\hline (I) Color & (J) Color & Mean Difference (I-J) & P-value \\
\hline Yellow & Blue & -8.37 & $<0.001$ \\
& Green & -2.22 & 0.195 \\
& Red & 8.14 & $<0.001$ \\
\hline \multirow{2}{*}{ Blue } & Yellow & 8.37 & $<0.001$ \\
& Green & 6.15 & $<0.001$ \\
& Red & 16.51 & $<0.001$ \\
\hline \multirow{2}{*}{ Green } & Yellow & 2.22 & 0.195 \\
& Blue & -6.15 & $<0.001$ \\
& Red & 10.36 & $<0.001$ \\
\hline \multirow{2}{*}{ Red } & Yellow & -8.14 & $<0.001$ \\
& Blue & -16.51 & $<0.001$ \\
& Green & -10.36 & $<0.001$ \\
\hline
\end{tabular}

which was statistically significant compared to other color stimuli $(\mathrm{P}<0.001)$. Although the mean reaction time of green color stimulus was significantly different from the red color stimuli $(\mathrm{P}<0.001)$, the $2.2 \mathrm{~ms}$ difference between the mean reaction time of green and yellow color stimuli was not statistically significant $(\mathrm{P}=0.195)$

\section{Discussion}

In the present study, it has been observed minimum and maximum mean reaction time for red and blue light stimuli, respectively, with a mean difference of about 16.5 msec. Also, the average reaction times of green and yellow light stimuli were found to be intermediate between the red and the blue. The results of previous studies of the reaction time of color stimuli indicated inconsistencies.

Consistent with the results of the present study, some studies $^{15,20-23}$ showed that reaction times to red stimuli were shorter than those to green or blue stimuli. Also, the results of Tomito et $\mathrm{al}^{24}$ study indicate that when the retina was illuminated with microelectrode penetration of single cones, the maximum number of cones is activated for red color, followed by blue and least response was for green color. The shorter reaction times of red light compared to green light can be explained by the number of light-sensitive photoreceptors with different colors and trichromatic theory, which demonstrates the tendency of photoreceptors to have different levels of sensitivity. ${ }^{25}$ Given that most percent of cone cells peaked for red light after stimulation, this may be the reason for the faster response of the visual system to redcolored light in the present study.

On the other hand, contrary to the findings of the present study and also many previous studies, ${ }^{15,20-23}$ it was reported that the reaction time for green color stimuli was less than that for red color stimuli. ${ }^{16,26}$ And the reason for this finding is based on the corpuscular theory.

According to corpuscular theory, ${ }^{27}$ light waves with different wavelengths have different energies, so the higher the wavelength, the less energy carries by it. Since the red light in the visible spectrum has the highest wavelength, it will carry the lowest amount of energy and thus provide a slower response. The greater energy carried by green light could stimulate the visual receptors faster when compared to red light. ${ }^{16}$

The results of the present study also showed the maximum and minimum reaction times for the blue and red light colors, respectively, which is inconsistent with the theory of the amount of energy carried by each colored light (corpuscular theory) and partly related to the relative number of cones 
activated in response to a particular colour of light. Given these explanations, it may be said that the cumulative effect of two opinions including the number of exciting photoreceptors and the energy carried by light can affect the visual reaction time together, so the simultaneous effect of these two factors leads to the real result.

Another finding of the present study was that the mean visual reaction time of the blue light stimulus response was longer than the other light stimuli. The possible reason for this finding may be that the signal processing time in the S-cone system is slightly longer than the other cone systems and so further stimulation of the system needed to lead to the perception of blue and purple hues. ${ }^{28,29}$

\section{Conclusion}

There are significant differences in the reaction time of the visual system for different colored light stimuli, which can be due to the different factors and systems involved in the visual processing, color perception and activation of cone cells. Further research will be needed to assess the impact of colored stimuli on visual reaction time.

\section{Ethics Approval and Informed Consent}

The study protocol adhered to the tenets of the Declaration of Helsinki and was approved by the institutional review board of the Iran University of Medical Sciences and the Steering Committees of the School of Rehabilitation Sciences. All patients signed a written informed consent to allow the evaluation of their clinical data.

\section{Acknowledgments}

The authors would like to extend their sincere appreciation to the School of Rehabilitation Sciences of Iran University of Medical Science staff for their assistance and co-operation in carrying out the visual reaction time test with Speed Anticipation and Reaction Tester (SART) software.

\section{Funding}

This study was supported by the Iran University of Medical Sciences.

\section{Disclosure}

The authors have no financial interest in any of the products mentioned in the manuscript and report no conflicts of interest in this work.

\section{References}

1. Mohan M, Thombre DP, Das AK, Subramanian N, Chandrasekar S. Reaction time in clinical diabetes mellitus. Indian $J$ Physiol Pharmacol. 1984;28(4):311-314.

2. Lofthus GK. Sensorimotor performance and limb preference. Percept Mot Skills. 1981;52(3):683-693. doi:10.2466/pms.1981.52.3.683

3. Das S, Gandhi A, Mondal S. Effect of premenstrual stress on audiovisual reaction time and audiogram. Indian J Physiol Pharmacol. 1997;41(1):67-70.

4. Solanki J, Joshi N, Shah C, Mehta HB, Gokhle PA. A study of correlation between auditory and visual reaction time in healthy adults. Int J Med Public Heal. 2012;2(2).

5. Draper S, McMorris T, Parker JK. Effect of acute exercise of differing intensities on simple and choice reaction and movement times. Psychol Sport Exerc. 2010;11(6):536-541. doi:10.1016/j. psychsport.2010.05.003

6. Collardeau M, Brisswalter J, Vercruyssen F, Audiffren M, Goubault C. Single and choice reaction time during prolonged exercise in trained subjects: influence of carbohydrate availability. Eur J Appl Physiol. 2001;86(2):150-156. doi:10.1007/s004210100513

7. Williams AM, Grant A. Training perceptual skill in sport. Int J Sport Psychol. 1999;30:194-220.

8. Milner AD. Chronometric analysis in neuropsychology. Neuropsychologia. 1986;24(1):115-128. doi:10.1016/0028-3932(86) 90045-X

9. Audiffren M, Tomporowski PD, Zagrodnik J. Acute aerobic exercise and information processing: energizing motor processes during a choice reaction time task. Acta Psychol (Amst). 2008;129 (3):410-419. doi:10.1016/j.actpsy.2008.09.006

10. Ito M. Fractionated reaction time as a function of magnitude of force in simple and choice conditions. Percept Mot Skills. 1997;85 (2):435-444. doi:10.2466/PMS.85.6.435-444

11. Galton F. Exhibition of instruments (1) for testing perception of differences of tint, and (2) for determining reaction-time. J Anthropol Inst Gt Britain Irel. 1890;19:27-29. doi:10.2307/ 2842529

12. Eckner JT, Kutcher JS, Richardson JK. Pilot evaluation of a novel clinical test of reaction time in National Collegiate Athletic Association Division I football players. J Athl Train. 2010;45 (4):327-332. doi:10.4085/1062-6050-45.4.327

13. Bleecker ML, Bolla-Wilson K, Agnew J, Meyers DA. Simple visual reaction time: sex and age differences. Dev Neuropsychol. 1987;3 (2):165-172. doi:10.1080/87565648709540372

14. Bamne SN, Fadia AD, Jadhav AV. Effect of colour and gender on human reaction time. Indian J Physiol Pharmacol. 2011;55(4):388.

15. Shenvi D, Balasubramanian P. A comparative study of visual and auditory reaction times in males and females. Indian $J$ Physiol Pharmacol. 1994;38:229.

16. Venkatesh D, Ramachandra DL, Suresh Babu N, Rajan BK. Impact of psychological stress, gender and colour on visual response latency. Indian J Physiol Pharmacol. 2002;46(3):333-337.

17. Bashore TR, Ridderinkhof KR. Older age, traumatic brain injury, and cognitive slowing: some convergent and divergent findings. Psychol Bull. 2002;128(1):151. doi:10.1037/0033-2909.128.1.151

18. Mohanraj S, Karthikeyan A. Comparison of visual reaction time in myopic subjects with emmetropic subjects. Natl J Physiol Pharm Pharmacol. 2017;7(2):194. doi:10.5455/njppp.

19. Nuri L, Shadmehr A, Ghotbi N, Attarbashi Moghadam B. Reaction time and anticipatory skill of athletes in open and closed skill-dominated sport. Eur J Sport Sci. 2013;13(5):431-436. doi:10.1080/17461391.2012.738712

20. Liang T, Piéron H. I Recherches sur la latence de la sensation lumineuse par la méthode de l'effet chronostéréoscopique. Annee Psychol. 1942;43(1):1-53. doi:10.3406/psy.1942.7871 
21. Pie'ron H. La sensation chromatique: Donne'e sur la latence proper et l'e'tablissement des sensation de coleur. Ann Psychol. 1932;32:1-29. doi:10.3406/psy.1931.5026

22. Batra A, Vyas S, Jeph D. Color difference on simple visual reaction time in young volunteers. Int J Clin Exp Physiol. 2014;1(4):311-313. doi:10.4103/2348-8093.149771

23. Kalyanshetti SB. Effect of colour of object on simple visual reaction time in normal subjects. J Krishna Inst Med Sci. 2014;3(1):96-98.

24. Detweiler DK. Circulation. In: Brobeck JR, editor. Best and Taylor's Physiological Basis of Medical Practice. 11 ed. Baltimore: Williams and Wilkins; 1979:984.
25. Wright WD. The present status of the trichromatic theory. Doc Ophthalmol. 1949;3(1):10-23. doi:10.1007/BF00162596

26. Nissen MJ, Pokorny J. Wavelength effects on simple reaction time. Percept Psychophys. 1977;22(5):457-462. doi:10.3758/BF03199511

27. Puri BR, Sharma IR. Principles of Physical Chemistry. New Delhi: Shoban Jal Nagin Chand and Co; 1997.

28. Wyszecki G, Stiles WS. Color Science: Concepts and Methods, Quantitative Data and Formulae. 2nd ed. New York: Wiley; 1982.

29. McKeefry DJ, Parry NRA, Murray IJ. Simple reaction times in color space: the influence of chromaticity, contrast, and cone opponency. Invest Ophthalmol Vis Sci. 2003;44(5):2267-2276. doi:10.1167/iovs.02-0772
Clinical Optometry

\section{Publish your work in this journal}

Clinical Optometry is an international, peer-reviewed, open access journal publishing original research, basic science, clinical and epidemiological studies, reviews and evaluations on clinical optometry. All aspects of patient care are addressed within the journal as well as the practice of optometry including economic and business analyses. Basic and clinical research papers are published that cover

Submit your manuscript here: https://www.dovepress.com/clinical-optometry-journal

\section{Dovepress}

all aspects of optics, refraction and its application to the theory and practice of optometry. The manuscript management system is completely online and includes a very quick and fair peer-review system, which is all easy to use. Visit http://www.dovepress.com/ testimonials.php to read real quotes from published authors. 